and the physiological variations of the electro-cardiogram, the various abnormalities and their indications are discussed in detail and profusely illustrated by exceptionally clear tracings. One specially interesting feature of the book is a series of short clinical histories with accompanying electrocardiograms.

In addition, the author supplies a useful glossary of the terms employed in this branch of medicine, a bibliography of the most important works in this field which have appeared between 1916 and 1935, and that essential for a book of reference, a very full general index.

\section{A TEXT-BOOK OF MENTAL DEFICIENCY}

\section{(Amentia).}

By A. F. TREdGold, M.D., F.R.C.P., F.R.S.E., Lecturer on Mental Deficiency, London University, Consulting Physician, University College Hospital. 6th Edition, Pp. xvi +536 . Baillière, Tindall \& Cox. 1937. Price 25/-.

The Report, published in 1908, of the Royal Commission appointed in 1904, to consider the Care and Control of the Feebleminded gives the number of aments in England and Wales in 1906 as about 150,000 , which was equivalent to about 4 per 1,000 of the population. In 1924, a joint committee of the Board of Education and the Board of Control reinvestigated the matter and in their Report published in 1929 they found the total number of aments in England and Wales to have been 314,000 , corresponding to some 8 per 1,000 of the population. After making due allowance for the more elaborate character of the joint committee's investigations which would account for some of the difference in the incidence of amentia, one is forced to the conclusion that though the number of mental defectives has not actually doubled itself in the 20 years' interval between the two investigations, there has undoubtedly been a very considerable increase in their percentage incidence. The subject of Mental Deficiency is, therefore, one of very great sociological importance.

The book before us, written by a leading authority on the subject, deals most interestingly and comprehensively with every phase and aspect of the problem, and in revising the work for the present edition Dr. Tredgold has not only incorporated the results of the numerous researches carried out in this field since the appearance of the last edition in 1929 (e.g., a full account is given of Phenylketonuria, or phenylpyruvic amentia, first described as recently as 1934), but has rewritten a number of chapters and added a section on the Chronological Development of the Normal Mind. The result is an up-to-date book which is encyclopædic in scope and is also a veritable mine of most authoritative information on the ætiology, classification, distribution, psychology, pathology, clinical examination (including a critical account of the various mental tests), diagnosis, prognosis, treatment and training of the various types of primary and secondary amentias, as well as on the legal and sociological aspects of mental deficiency. Moreovèr, the style in which it is written is so "palatable," and the excellent pictorial embellishments-in the form of well chosen and artistically reproduced photographs, illustrating the physiognomical and concomitant features of the various types of amentia-are so "appetising" that, like a gastronomically prepared meal, the book is eagerly "devoured," easily " digested " and pleasantly " absorbed."

It is quite unnecessary-even if space permitted - to give a general survey of the book which must be already known to many thousands of people. We would, however, like to call attention to a few matters of some interest. Dr. Tredgold believes that while an idiotic child may result from a conception taking place during a state of alcoholic intoxication, it only occurs with extreme rarity (p. 39). The author has either overlooked, or intentionally ignored, Pearson and Elderton's mathematical analysis of extensive statistics on the subject, in 
which they came to the conclusion that there is no evidence that such a result occurs at all. We would also take exception to the author's remark on p. 207, that although the term "Mongolism" as applied to the type of amentia going by that name, is unfortunate, " change is now undesirable." We, on the contrary, think it most desirable that the term should be dropped though it may be very difficult to find a suitable substitute. LangdonDown introduced it some 70 years ago, as one of four ethnic groups of mental deficiency, the other three being Ethiopianism, Caucasianism and American Indianism, in accordance with their supposed physiognomical resemblances. The other three groups have long since been given up, and the term Mongolism should follow them into the limbo of forgotten things. Not only are the slanting palpebral fissures practically the sole physiognomical resemblance to racial Mongols, but this type of primary amentia is in fact rarer in the Mongolian than in the White races. The retention of the term is therefore unfair and should be eliminated as have been the names "English" and "French" disease as the designations for rickets and syphilis respectively. On p. 522, Dr. Tredgold . categorically dismisses as fallacious the idea implied by Dryden's well-known lines of any relationship between madness and " great wit," but his most interesting account of " Idiots Savants " and the "Genius of Earlwood Asylum" (pp. 306-317) tend to refute his own scepticism. Another regrettable fact-for which the author cannot, of course, be held responsible -is the lack of uniformity prevailing in different parts of the world regarding the terminology and grading of the different types of amentia. Thus while the terms "Idiocy" and "Imbecility" connote the same respective types in this country and in America, the term "Feeble mindedness" which is used in this country to denote the mildest grade of defect, comprises in America the whole order of amentia, and the term "Moron" is used by them as synonymous with the third or highest grade of amentia. Further, while our system of grading is based on the degree of the sufferer's social incapacity, the Americans grade him according to the size of his intelligence quotient. It should not be beyond the competence of an international committee to arrive at some uniform method of standardizing the grades and thus obviating the unnecessary but inevitable confusion.

Dr. Tredgold's book is indispensable to all mental specialists, as well as to those who are concerned with the diagnosis and certification of mental defectives under the various Acts. We would also urge its perusal by every medical practitioner who takes a practical or academic interest in all branches of his profession.

\section{DISEASES OF THE NOSE, THROAT AND EAR.}

By J. Simson Hall. E. \& S. Livingstone. 1937. Price 10/6.

Dr. J. Simson Hall is the author of a book of moderate size on Diseases of the Nose, Throat and Ear. The book is intended as a general guide for students an $\$$ practitioners, and contains full description of the usual methods of examination, and provides some information, however brief, on most of the conditions which are commonly encountered in practice. The size of such a book naturally does not allow any comprehensive descriptions, and some omissions are no doubt inevitable. No reference is made, for example, to aspergillosis of the ear nor to the associated paralyses which affect the larynx and pharynx. Both these conditions may not be common, but they are commoner than is usually supposed and are often overlooked on that account for long periods. Dr. Hall must be well aware that he is entering on a field in which there is brisk competition and that his book does not contain anything that is not to be found in other books of similar scope, so that although his own is very suitable for the purpose intended, it can only succeed by its superior merits. The book is largely written in the didactic style, which although of value in enforcing teaching, leads to an appreciable waste of words and space. A more concise style would have enabled the author to supply more detailed instruction and in many places more precise directions. It is, however, pleasantly written and well illustrated and fairly achieves the aims of its author. 